\title{
Post-Transplant Lymphoproliferative Disorder
}

National Cancer Institute

\section{Source}

National Cancer Institute. Post-Transplant Lymphoproliferative Disorder. NCI Thesaurus.

Code $C 4727$.

Post-transplant lymphoproliferative disorder (PTLD) is a polyclonal (benign) or clonal

(malignant) proliferation of lymphoid cells that develops as a consequence of

immunosuppression in a recipient of a solid organ or bone marrow allograft. PT LDs

comprise a spectrum ranging from early, Epstein-Barr virus (EBV)-driven polyclonal

lymphoid proliferations to EBV-positive or EBV- negative lymphomas of predominantly B-

cell or less often T-cell type. (WHO, 2001) 